\title{
NASA Planetary Research and Analysis: What is R\&A?
}

Mark V. Sykes (sykes@psi.edu, 520-622-6300) ${ }^{1}$, Julie Castillo-Rogez ${ }^{2}$, Christina Richey², Paul K. Byrne $^{3}$

1Planetary Science Institute, 1700 East Fort Lowell, Suite 106, Tucson AZ 85719

2Jet Propulsion Laboratory, California Institute of Technology, Pasadena CA 91109

${ }^{3}$ North Carolina State University, Raleigh NC 27695 


\section{EXECUTIVE SUMMARY}

\section{Key Findings}

- While the planetary community generally considers $R \& A$ the basic science and data analysis programs in the ROSES calls, with all openly competed, there is significant variation in what NASA considers R\&A. This was manifested by separate inconsistent budget profiles for these programs for FY2011-FY2016, provided by NASA in separate submissions in 2017 to the NRC Vision and Voyages Mid-term Assessment panel. The discrepancy in budgets for one fiscal year exceeded $50 \%$. This discrepancy was only possible because the most recent planetary Decadal Survey (NRC, 2011) did not clearly and specifically define "R\&A".

- In the prior two planetary Decadal Studies (NRC, 2003, 2011), as well as in numerous other Academy reports spanning decades, R\&A has been found to be critical to NASA's mission and to develop and sustain the workforce necessary to advance its strategic objectives.

- Reallocation of R\&A funding through NASA initiatives such as the Internal Scientist Funding Model weakens the viability of the R\&A programs and their support for a healthy and vibrant planetary science community in the U.S.

\section{Recommendations}

(1) The next Decadal Survey must rigorously define what is included and, just as importantly, what is not included in the phrase "R\&A programs". For example, The Decadal Survey must say whether or not R\&A includes programs that are not openly competed; whether its programs must be in ROSES calls; whether they can be programs designed to provide support for active missions (which would nominally be part of mission budgets); and whether R\&A encompasses technology/instrument development programs, which in the latest Decadal Survey had a funding recommendation separate from $R \& A$ programs.

(2) NASA needs to provide to the Decadal Survey a list of all program elements, along with their WBS numbers, within the NASA Planetary Science Division's lowest-level federal budget lines for 2020 (every non-bolded budget line in Table 3 as well as Radioisotope Power, which does not have any lower-level budget lines). Their budgets should sum up to the budget of the line within which they reside (e.g., Mars Exploration). NASA needs to provide a short description of all these program elements and indicate those it nominally considers to be "R\&A". This should be done for several prior years as well.

(3) The next Decadal Survey must determine for each program element provided by NASA in (2) whether that element falls within or outside of the definition for "R\&A" from (1). Such an exercise will inform potential adjustments that need to be made to the definition from (1). This exercise should be laid out in its entirety in an appendix and will be valuable in the assignment of new program elements during the period covered by the next Decadal Survey report. 
(4) Programs designed to support civil servant and other NASA center scientists, such as the Internal Scientist Funding Model, should not be classified as "R\&A programs" nor be funded by them. The need for civil servant and other NASA Center scientists and how they should be funded as part of a Center or other agency budget is a valuable discussion to be had in an open forum. All research funded by an R\&A program should go through the same proposal process together.

(5) After the end of every fiscal year, NASA should be required to publish the accrued expenses of every R\&A program for that year, along with its WBS number, the sum of which would be considered the "R\&A budget" for that year. This could then be directly compared against any Decadal funding recommendation. Doing so would also allow for independent assessment of the extent to which program elements included by NASA are consistent with the Decadal definition from (1) for "R\&A" programs.

Figure 1. R\&A is the foundation on which all of NASA planetary exploration rests (Sykes 2006)
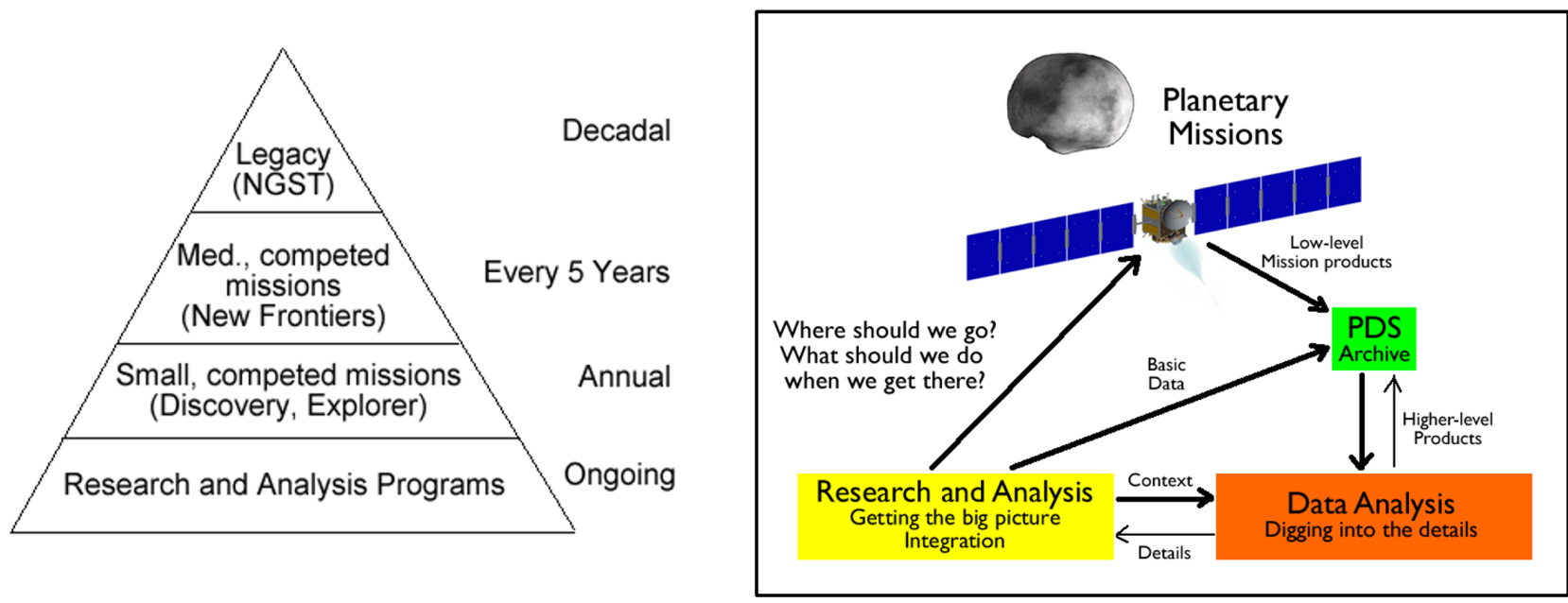

\section{THE IMPORTANCE OF RESEARCH AND ANALYSIS PROGRAMS}

"It seems inevitable that specific space missions will continue to occupy the foreground of NASA's image, especially for those who look at the agency from some distance. Officials and policy makers, however, must give equal attention to the activities of R\&DA, which are essential in meeting the agency's overarching mission to expand human knowledge." (NRC, 1998)

"R\&A furnishes the context in which the results from missions can be correctly interpreted. Furthermore, active R\&A programs are a prime breeding ground for principal investigators and team members of forthcoming flight missions. Healthy R\&A programs are of paramount importance and constitute a necessary 
precondition for effective missions. This conclusion has been stated repeatedly and forcefully before." (NRC, 2003).

"The research related to planetary missions begins well before a mission is formulated and funded, and continues long after it is over. Research provides both the foundation for interpreting data collected by spacecraft as well as the guidance and context for identifying new scientifically compelling missions.

Research and analysis programs allow the maximum possible science return to be harvested from missions." (NRC, 2011)

For decades, the critical role played by R\&A programs in executing NASA's mission has been clearly articulated by the NRC and others and is illustrated in Fig. 1. Yet the continuing instability of these programs, and NASA's fluid position on what should be considered an R\&A program, indicates the low priority with which they have been regarded by the agency.

\section{WHAT IS "RESEARCH AND ANALYSIS"?}

Table 1. FY2020 Federal Budget Request for NASA Planetary Science Division. All lines with budget numbers are referred to as "budget lines" in this paper.

\section{FY 2020 PREsident's Budget REQUEST SummaRY}

\begin{tabular}{|c|c|c|c|c|c|c|c|}
\hline \multirow[b]{2}{*}{ Budget Authority ( $\$$ in millions) } & \multicolumn{7}{|c|}{ Fiscal Year } \\
\hline & $\begin{array}{c}\text { Operatin } \\
\text { g Plan } \\
2018\end{array}$ & $\begin{array}{c}\text { Enacted } \\
2019\end{array}$ & $\begin{array}{l}\text { PBR } \\
2020\end{array}$ & 2021 & 2022 & 2023 & 2024 \\
\hline Planetary Science & $2,217.9$ & - & $2,622.1$ & $2,577.3$ & $2,629.4$ & $2,402.4$ & $2,350.9$ \\
\hline Planetary Science Research & 279.5 & - & 266.2 & 272.6 & 268.6 & 270.2 & 301.9 \\
\hline $\begin{array}{l}\text { Planetary Science Research and } \\
\text { Analysis }\end{array}$ & 197.9 & - & 183.8 & 188.0 & 181.9 & 180.9 & 204.7 \\
\hline Other Missions and Data Analysis & 81.6 & - & 82.4 & 84.7 & 86.7 & 89.3 & 97.2 \\
\hline Planetary Defense & 76.0 & - & 150.0 & 150.0 & 150.0 & 99.5 & 100.0 \\
\hline DART & 41.0 & 98.0 & 72.4 & 66.4 & 9.1 & 4.5 & - \\
\hline Other Missions and Data Analysis & 35.0 & - & 77.6 & 83.6 & 140.9 & 95.0 & 100.0 \\
\hline Lunar Discovery and Exploration & 22.0 & - & 210.0 & 327.0 & 417.0 & 441.0 & 458.0 \\
\hline Discovery & 258.3 & - & 502.7 & 393.4 & 364.4 & 371.6 & 371.6 \\
\hline Lucy & 81.4 & 170.5 & 218.5 & 153.4 & 56.0 & 16.5 & 18.6 \\
\hline Psyche & 42.0 & - & 213.2 & 181.9 & 156.4 & 33.7 & 24.0 \\
\hline Other Missions and Data Analysis & 134.9 & - & 71.0 & 58.1 & 152.0 & 321.4 & 329.0 \\
\hline New Frontiers & 88.1 & - & 190.4 & 261.2 & 341.9 & 387.3 & 291.7 \\
\hline Mars Exploration & 678.0 & - & 546.5 & 472.2 & 481.7 & 506.1 & 590.1 \\
\hline Mars Rover 2020 & 505.8 & 305.6 & 278.0 & 145.0 & 110.0 & 60.0 & 60.0 \\
\hline Other Missions and Data Analysis & 172.2 & - & 268.5 & 327.2 & 371.7 & 446.1 & 530.1 \\
\hline Outer Planets and Ocean Worlds & 676.2 & - & 608.4 & 549.6 & 463.7 & 224.2 & 68.8 \\
\hline Jupiter Europa & 595.0 & 740.0 & 592.6 & 530.8 & 445.1 & 207.3 & 54.6 \\
\hline Other Missions and Data Analysis & 81.2 & - & 15.8 & 18.8 & 18.6 & 16.9 & 14.2 \\
\hline Radioisotope Power & 139.8 & - & 147.9 & 151.3 & 142.1 & 102.5 & 168.8 \\
\hline
\end{tabular}


Table 2. A sample of program elements within PSD budget lines, some of which are considered traditional R\&A programs and others are not.

\author{
Planetary R\&A Programs \\ 811073.02.01 Planetary Geology \& Geophysics \\ 811073.02.02 Cosmochemistry \\ 811073.02.03 Planetary Astronomy (PAST) \\ 811073.02.06 Planetary Instrument Definition \& Development (PIDDP) \\ 811073.02.15 Lunar and Planetary Institute Support \\ 811073.02.25 Antarctic Meteorites \\ 811073.02.35 Solar System Workings \\ 811073.02.36 Habitable Worlds
}

\title{
Lunar Quest
}

964946.02.01 Planetary Geology \& Geophysics

964946.02.04 Lunar Reconnaissance Orbiter Participating Scientist Program

964946.02.06 Lunar Advanced Science \& Exploration Research (LASER)

964946.02.12 Moon and Mars Mission Activities (MAMMA)

\section{Discovery}

231402.02.01 Laboratory Analysis of Returned Samples (LARS)

231402.02.02 Discovery Data Analysis Program

231402.02.05 Dawn Participating Scientist Program

\section{Outer Planets}

202844.02.01 Cassini Data Analysis Program (CDAP)

202844.02.02 Outer Planets Research (OPR)

202844.02.03 Cassini Participating Scientist Program

\section{Mars Exploration}

203959.02.03 Mars Data Analysis Program (MDAP)

203959.02.04 Mars Phoenix Data Analysis Program

In the first planetary Decadal Survey (NRC, 2003), research and analysis programs cover "basic theory, modeling studies, laboratory experiments, ground-based observations, long-term data analysis, and comparative investigations." They are also programs by which "data returned by flight missions are converted into new understanding, advancing the boundaries of what is known." In the second planetary Decadal Survey (NRC, 2011), "along with analysis of spacecraft 
data, $[R \& A]$ portfolios include laboratory experiments, theoretical studies, fieldwork using Earth analogs, planetary geologic mapping, and analysis of data from Earth-based telescopes."

Traditionally, R\&A programs include openly competed ROSES programs of basic research and spacecraft data analysis. In the NASA Planetary Science Division (PSD) budget (Table 1), these programs do not constitute a single budget line. Even "Planetary Science Research and Analysis" under "Planetary Science Research" does not include all R\&A programs and has program elements that would not traditionally be considered $R \& A$. $R \& A$ programs are scattered across almost every budget line within the PSD budget, illustrated in Table 2. Some of the examples in Table 2 are old programs that no longer exist and some may move around to different budget lines. The key to tracking them is the WBS number on the left.

When looking at program elements within a budget line, new questions arise as to whether a given program element should be classified as an "R\&A" program. Participating Scientist Programs support active missions. Should they be included? The Lunar and Planetary Institute does a lot of directed activity both in research and in organizing conferences; it is also rarely competed. Antarctic Meteorites is directed activity taken over by NASA from NSF and is not a competed program in ROSES. All of this activity may be consistent at some level with the descriptions of R\&A activities, making it difficult to categorize. In addition, there are times when a program (such as Planetary Geology and Geophysics in Table 2) may be funded as different program elements in different funding lines. One would need to understand what each of these elements covers to determine whether both are R\&A programs.

Defining "R\&A" as merely a sum of activities allows programs to be included for which those activities may be only an incidental component.

\section{EVIDENCE FOR LACK OF DEFINITIONAL CONSTRAINT BY NASA}

In 2017, an NRC committee examined mid-term compliance by NASA with the most recent Decadal Survey recommendations (Vision and Voyages Mid-term Assessment, https://sites.nationalacademies.org/ssb/currentprojects/ssb_177619). During its meetings, NASA provided funding profiles for the R\&A programs in comparison with its determination of those Decadal recommendations. These funding profiles were challenged by Sykes (2017) as inaccurate, which resulted in two subsequent submissions by NASA, all of which was summarized in Table 3 for testimony before the House Space and Aeronautics Subcommittee (Sykes, 2019).

The Sykes (2017) numbers in Table 3 assumed the following definition for R\&A programs:

"Research and Analysis Programs = PI led, competed, basic research and data analysis programs in ROSES.

Research and Analysis Programs $\neq$ Directed activities, facility support (e.g., IRTF), PDS, specific mission support programs, technology programs. Technology programs are separately addressed in the decadal survey." 
Budget numbers for program elements were obtained from NASA via Freedom of Information Act (FOIA) requests or otherwise made publicly available by the agency. All data and assumptions used are given in Sykes (2017). Program element-level budget numbers for the NASA numbers were not provided by the agency.

Table 3. Three funding profiles for FY2011 to FY2016 submitted by NASA to the NRC Mid-term review panel, compared with budgets calculated by Sykes (2019).

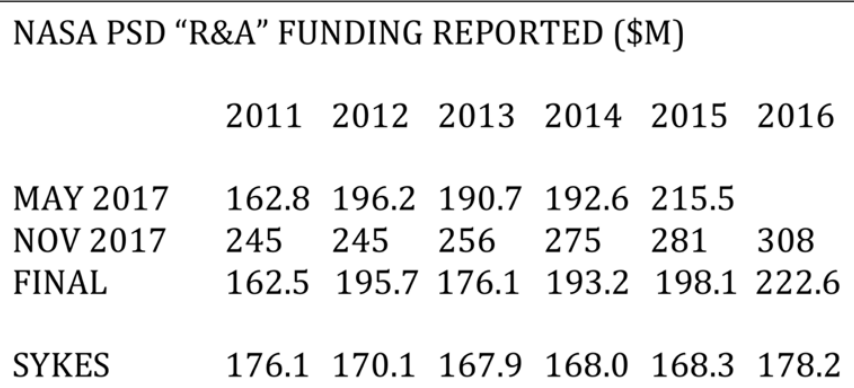

In Table 3, the difference between the budget numbers of Sykes and NASA (May 2017) indicates these parties were not defining R\&A programs in the same way (one assumes the budget numbers for program elements used by both were the same since they all derived from NASA). However, the wild differences among NASA's own submissions-more than $50 \%$ in one case-indicates considerable flexibility in how NASA could substantially change what it considered to be R\&A programs on timescales of months.

A review of the descriptive language in prior Decadal Survey reports (e.g., first paragraph of Section 2) suggests a perception that it was broadly "known" by the planetary science community and NASA which programs were R\&A and which were not. The next Decadal Survey report must give clear definitional guidance to NASA about what programs can be considered R\&A and what programs cannot be included. In making a clear definition, it is also necessary that the Decadal Survey go through the exercise of comparing to that definition all program elements in all PSD budget lines in FY2020 and a few prior years and deciding the sum of programs that should be identified as "R\&A". The value of such an exercise is that it will likely result in a refinement of the definition for R\&A programs by the Survey and will provide good guidance to the agency for future years as new program elements are created.

\section{TRACKING R\&A HEALTH AND DECADAL COMPLIANCE}

It is not possible to look at the publicly available President's Budget Request (Table 1) or the subsequent Federal budget passed by Congress and determine the level at which R\&A programs will be funded if approved as proposed. This is because, as seen in Table 2, R\&A programs make up just a portion of some of the budget lines seen in Table 1. 
The only way to determine the health of the "R\&A program," and to ensure that it is comprised of program elements consistent with a Decadal definition, is for NASA to regularly (i.e., annually) provide a report on the prior fiscal year that includes the name of the program elements included in R\&A, their WBS numbers, and their total accrued costs for that fiscal year. Added together, these costs should equal the budget recommended by the Decadal Survey for that fiscal year. This information has been provided to the community at LPSC on occasion in the past decade. It has also been obtained through Freedom of Information Act requests, but this latter action should be unnecessary. These data could be posted along with other detailed information about R\&A and other programs on the NASA SARA website.

\section{A NOTE ON THE INTERNAL SCIENTIST FUNDING MODEL}

The Internal Scientist Funding Model is a program that has been reallocating funds from R\&A programs to NASA Center scientists independent of the open competition process to which scientists from other organizations are subject (New, 2019). It should not be considered part of the R\&A program and should be funded separately. The extent to which resources from $R \& A$ programs have been sent to NASA Centers (primarily NASA Goddard) is unknown at this time. ISFM raises important questions about how a NASA Center science workforce is rationalized, scoped, and funded.

\section{REFERENCES}

New, M. 2019. SMD Implementation Plan for the Internal Scientist Funding Model. NASA, internal (July 15, 2019). http://planetarypolicy.org/ISFM/ISFM-implementation-v14.pdf

NRC, 1998. Supporting Research and Data Analysis in NASA's Science Programs: Engines for Innovation and Synthesis (1998). https://www.nap.edu/download/6311

NRC, 2003. New Frontiers in the Solar System: An Integrated Exploration Strategy. http://www.nap.edu/catalog/10432.html

NRC, 2011. Vision and Voyages for Planetary Science in the Decade 2013-2022. http://www.nap.edu/catalog/13117.html

Sykes, M. 2006. Private communication to DPS Federal Relations Subcommittee.

Sykes, M. 2017. Analysis of NASA PSD Compliance with Decadal Survey Recommendations for Research and Analysis Funding. http://planetarypolicy.org/RA_Decadal_Midterm_Review_MVS.pdf

Sykes, M. 2019. https://science.house.gov/hearings/discovery-on-the-frontiers-of-spaceexploring-nasas-science-mission 